\title{
China's three-year health reform program and equity in sanitation improvement: a panel analysis
}

Xiaolong $\mathrm{Li}^{1}$, Yanqing Miao ${ }^{2^{*}}$ and Wenjing Chen ${ }^{1}$

\begin{abstract}
Background: Accessible improved sanitation is critical to child health, and inequities in improved sanitation can be interpreted as health inequities across socio-economic groups. From 2009 to 2011, the Chinese government invested 4.448 billion yuan for rural sanitation improvement through a 3-year health reform program. This study assesses the inequity of sanitation improvement in rural China from 2003 to 2011 and examines whether the 3-year health reform program promoted equity in sanitation improvement.

Methods: Data from the China Health Statistics Yearbooks of 2004 to 2012 and the National Bureau of Statistics of China were used to create the concentration curve $(\mathrm{CC})$, concentration index $(\mathrm{Cl})$, and absolute concentration index (ACl) of improved sanitation. Data of central investment for sanitation improvement in each province of China for 2009, 2010, and 2011 was gained through correspondence and used to create the CC and Cl for investment.

Results: Although the Cls of improved sanitation are lower than the Cls of the net income of rural residents, the latter have an obvious downtrend. The Cls of improved sanitation increased from 2003 until 2008 and started to drop in 2009. As a result, by 2011, the Cls of improved sanitation had reached their 2003 levels. The ACl of improved sanitation decreased slightly from 2003 to 2008, but declined sharply from 2009 to 2011. The Cls of central investment for 2009, 2010, and 2011 are negative and the CCs of central investment are above the line of absolute equality, indicating that investments had been concentrated more on poorer provinces and regions.
\end{abstract}

Conclusions: The equality of rural residents' net income has been improving each year, whereas equity in sanitation improvement deteriorated from 2003 to 2008. However, equity in sanitation improvement has increased since 2009 due to central investment in sanitation improvement during the 3-year health reform program that benefits low-income areas more. It is clear that the 3-year health reform program played an important role in promoting the level and equity of sanitation improvement.

Keywords: Inequity, Improved sanitation, Three-year health reform program, Central investment, Concentration curve, Concentration index, Absolute concentration index

\section{Background}

Globally, approximately 2.4 million deaths $(4.2 \%$ of all deaths) [1] could be prevented each year if everyone practised appropriate hygiene and had good, reliable sanitation and drinking water. Most of these deaths were of children in developing countries and primarily resulted from diarrhoea and subsequent malnutrition, as

\footnotetext{
*Correspondence: miaohanxinyun@126.com

${ }^{2}$ China National Health Development Research Center, NHFPC, Beijing 100083, China

Full list of author information is available at the end of the article
}

well as from other diseases attributable to malnutrition. Although it is rarely discussed alongside the three major diseases that attract attention from the international public health community, HIV/AIDS, tuberculosis, and malaria, diarrhoea alone kills more children each year than these three combined [2]. The keys to diarrhoea's control are hygiene, sanitation, and water.

In 2010, Bartram and Caimcross noted that "The household burden weighs most heavily upon the poor, but well-conceived sanitation and water programmes can weaken the link between poverty and disease and so 
contribute to health equity" [3]. Sanitation improvement in rural China deserves close attention because China is one of the largest developing countries in the world, and it has the largest population in rural areas [4]. The traditional causes of illness, such as infections resulting from poor sanitation and hygiene, are unevenly distributed across China's diverse geographic landscape as a result of regional differences in economic development, culture and environmental factors [5-7]. The Chinese government has attached special importance to sanitation improvement for more than a decade and has incorporated the improvement of sanitation in rural areas into its national 5-year plan since the 1990 s. In 2009 , to promote public health service levels and equity, the Chinese government launched a 3-year health reform program. The opinions of the Communist Party of China (CPC) Central Committee and the State Council on widening the medical and health system reform indicated that government input in health services would be gradually increased [8]. The program aimed to alleviate the burden of expensive medical bills on citizens and increase their access to health care services [9]. In addition, the government stated that increasing spending on primary healthcare institutions was one of the five top priorities this plan. According to a 2012 report from the Ministry of Finance, from 2009 to 2011, the government invested approximately 1409.9 billion yuan (approximately US\$ 206 billion) in health care, and $44 \%$ of these funds were allocated for primary healthcare institutions [10]. In these 3 years, the Chinese government invested a total of 4.448 billion yuan for rural sanitation improvement. The main focus of the sanitation improvement program is helping rural residents build and use an improved sanitation system that requires secure access to a hygienic latrine, as well as treatment and safe disposal of sewage or wastewater. Large inputs brought high returns, and by the end of 2011, China had built $180,185,000$ improved sanitation facilities in rural areas, of which 10,289,000 were completed in 2011 [11]. In addition, the coverage rate of improved sanitation in rural China reached $69.2 \%$ in 2011 [12]. Figure 1 shows that the domestic coverage rate of improved sanitation in rural areas from 2003 to 2011 increased year by year.

In terms of the disparity in sanitation coverage rates among different regions, by the end of 2011, the highest was $98 \%$ in Shanghai (rural per capita net income of $16,053.8$ yuan in 2011) and the lowest was $40.9 \%$ in Guizhou Province (rural per capita net income of 4,145.4 yuan in 2011) [13]. These data show that the sanitation coverage rate varies greatly among different regions due to substantial gaps in economic development levels, efficiency of government execution, and other factors. However, research on the equity of sanitation improvement in rural China is sparse, and the existing research does not include discussion of the distribution of central investment in sanitation improvement during the 3-year health reform program from 2009 to 2011.

Among the different measures used for assessing inequity of water and sanitation improvement, the most common is the concentration index (CI) [14-17]. The relative CI does not take into account the level of a certain variable within a population, only how much it varies. Some researchers use the absolute concentration index (ACI) to measure public health condition and its equity simultaneously [18] because both public health condition and its equity are vital in public health policy. However, only a few studies focusing on ACIs are available [19-21]. To date, no researchers have used ACI to study sanitation improvement and related problems.

Therefore, we used the provincial panel data to assess inequity in sanitation improvement with an approach of

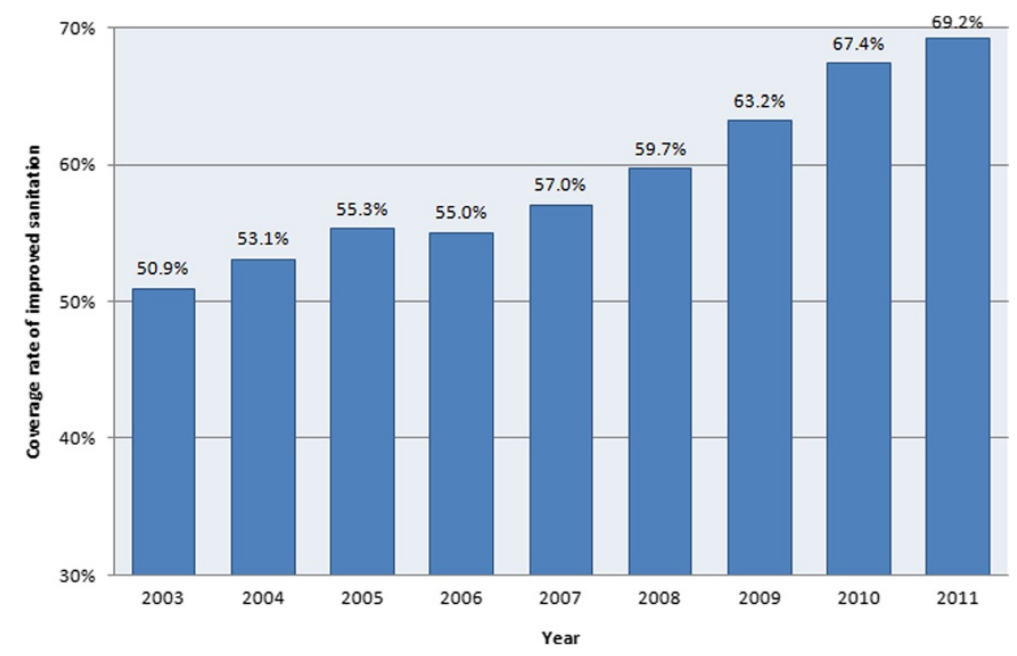

Figure 1 Coverage rate of improved sanitation in rural China from 2003 to 2011. 
calculating the $\mathrm{CI}$ and $\mathrm{ACI}$ of improved sanitation and examine whether the 3-year health reform program promoted equity in sanitation improvement. A number of studies have revealed that income and government intervention are major determinants of sanitation improvement [22-24], so we also calculated the CI of rural residents' net incomes as a reference and studied the distribution of central investment in 3-year health reform program from 2009 to 2011.

\section{Methods}

\section{Data resources}

The gross number of households and households with improved sanitation in rural China are from the China Health Statistics Yearbooks of 2004, 2005, 2006, 2007, 2008, 2009, 2010, 2011, and 2012. Peking Union Medical College Press publishes the China Health Statistics Yearbook annually, and the yearbook reflects China's annual health career development situation and resident health status information. The yearbook is a collection of national health development in 31 provinces, autonomous regions and municipalities directly under the Central Government and includes statistics for the current level of residents' health. Every yearbook incorporates contents for the end of the previous year. For example, the China Health Statistics Yearbook 2012 incorporates contents for the end of 2011. The yearbook is based on information from multiple sources, and the data for sanitation is from the annual health statistics report.

Rural residents' net incomes from 2003 to 2011 are from the China Statistical Yearbook. The amount of central investment for sanitation improvement in each province in 2009, 2010, and 2011 was obtained through correspondence from the Patriotic Public Health Campaign Committee of each province, which is in charge of specific implementation of the national health program, including sanitation improvement. Table 1 shows the results of this correspondence. The data in this study covered all provinces in China except Tibet.

\section{Concentration Curve (CC)}

The construction approach to the $\mathrm{CC}$ is similar to the approach for building a Lorenz curve. The horizontal axis is the cumulative proportion of the population and is ranked by socioeconomic status, beginning with the least advantaged. The vertical axis is the cumulative distribution of a parameter such as improved sanitation or central investment [25-28]. Compared with the curve of absolute equality, the $\mathrm{CC}$ will deviate from the right angle bisector if the distribution of the indicator is uneven among populations of different socioeconomic status: the more uneven the indicator, the more severe the deviation. The socioeconomic status of the population
Table 1 Central investment for sanitation improvement in each province in 2009, 2010, and 2011 (in millions of yuan)

\begin{tabular}{|c|c|c|c|}
\hline Province & 2009 & 2010 & 2011 \\
\hline Gansu & 55.16 & 68 & 55 \\
\hline Guizhou & 66 & 25 & 25 \\
\hline Qinghai & 26.48 & 15 & 15 \\
\hline Yunnan & 63.4 & 64 & 95 \\
\hline Shaanxi & 80.055 & 76.5 & 110 \\
\hline Xinjiang & 47.2 & 48 & 95 \\
\hline Guangxi & 18.4 & 110.8 & 75 \\
\hline Ningxia & 26.48 & 8 & 25 \\
\hline Shanxi & 63.92 & 40 & 25 \\
\hline Sichuan & 87.28 & 56 & 100 \\
\hline Chongqing & 75.44 & 80 & 115 \\
\hline Anhui & 70 & 64 & 80 \\
\hline Hainan & 33.2 & 20 & 15 \\
\hline Henan & 40 & 40 & 60 \\
\hline Hunan & 14 & 138.5 & 100 \\
\hline Neimenggu & 61.84 & 48 & 55 \\
\hline Hubei & 100 & 97.2 & 75 \\
\hline Jiangxi & 69 & 64 & 100 \\
\hline Hebei & 67.86 & 52 & 40 \\
\hline Heilongjiang & 60.1 & 40 & 60 \\
\hline Jilin & 61 & 56 & 35 \\
\hline Liaoning & 8.75 & 44.52 & 33 \\
\hline Shandong & 20 & 20 & 20 \\
\hline Fujian & 27.27 & 48 & 9 \\
\hline Guangdong & 25.91 & 45 & 42.76 \\
\hline Jiangsu & 75 & 75 & 75 \\
\hline Tianjin & 12.12 & 0 & 12.12 \\
\hline Zhejiang & 28.096 & 27 & 30 \\
\hline Beijing & 12.12 & 21 & 20 \\
\hline Shanghai & 0 & 0 & 0 \\
\hline
\end{tabular}

upon which the indicator is concentrated can also be interpreted from the shape of the curve.

The CC is not always a convex curve that monotonically increases because the cumulative parameter of vertical axis may be sorted differently from the parameter of the horizontal axis.

\section{Concentration Index (Cl)}

The $\mathrm{CI}$ is defined as twice the area between the CC and the line of equality. Thus, when $\mathrm{CC}$ coincides with the line of equality, the $\mathrm{CI}$ equals 0 . However, when the $\mathrm{CC}$ is above the equality line, the $\mathrm{CI}$ takes a negative value, 
and when the $\mathrm{CC}$ is below the equality line, the $\mathrm{CI}$ takes a positive value. The CI is bound between -1 and +1 [29].

In our study, the CI summarizes the CC and quantifies the degree of economic-related inequality in improved sanitation. Broadly speaking, the CI shows the relationship between the situation of sanitation improvement and economic status; it indicates the direction of the relationship and its magnitude echoes both the strength of the relationship and the degree of variability in the distribution of improved sanitation.

Suppose we have K provinces, and they are sorted by income from low to high. There are $n_{1}, n_{2}, n_{3} \ldots n_{K-1}, n_{K}$ households in these provinces respectively and $\sigma_{1}, \sigma_{2}, \sigma_{3}$ $\ldots \sigma_{K-1}, \sigma_{K}$ coverage rate of improved sanitation. Then, the total households are $n=n_{1}+n_{2}+n_{3}+\ldots+n_{K-1}+n_{K}$, with the weight corresponding to ith province: $\mathrm{w}_{\mathrm{i}}=\frac{\mathrm{n}_{\mathrm{i}}}{\mathrm{n}}$.

We used integration to measure twice the area between the $\mathrm{CC}$ and the line of equality. The $C I$ in our model is:

$$
\mathrm{CI}=\frac{2}{\mu} \sum_{\mathrm{i}=1}^{\mathrm{K}} \mathrm{y}_{\mathrm{i}} \mathrm{R}_{\mathrm{i}}-1
$$

Where $\mu$ is the coverage rate of improved sanitation of China and can be computed as:

$$
\mu=\sum_{1}^{\mathrm{n}} \mathrm{w}_{\mathrm{i}} \sigma_{\mathrm{i}}
$$

$R_{\mathrm{i}}$ is the relative rank of the ith province, defined as:

$$
\mathrm{R}_{i}=\frac{1}{2} \cdot \frac{\sum_{j=1}^{i-1} n_{j}+\sum_{\mathrm{j}=1}^{i} n_{j}}{n}
$$

and indicating the cumulative proportion of the population up to the midpoint of each group interval [26].

$y_{i}$ is the proportion of improved sanitation in ith province to the total households and can also be treated as the synthesis score, which can be computed as:

$$
\mathrm{y}_{\mathrm{i}}=\mathrm{w}_{\mathrm{i}} \sigma_{\mathrm{i}}
$$

To calculate integration, we must first calculate the differential. Then, the area between the absolute equality line and the $C C$ line can be divided into $\mathrm{K}$ small areas, and each area can be treated as a trapezoid (approximately). $R_{i}$ is the half of the sum of ith trapezoid's upper base and lower base.

\section{Absolute Concentration Index $(\mathrm{ACl})$}

The ACI of health is obtained by multiplying the health $\mathrm{CI}$ with the mean of health variable [27], while the ACI of improved sanitation is defined as follows:

$$
A C I=C \cdot(1-\mu)
$$

where $C$ is the improved sanitation $C I$ and $\mu$ is the coverage rate of improved sanitation. The value of ACI decreases when imparity in the improved sanitation coverage rate for all the provinces decreases or the improved sanitation coverage rates for each province increases at the same time. Therefore, the ACI of improved sanitation evaluates equality and progress in sanitation improvement simultaneously.

\section{Results}

CCs of central investment, improved sanitation, and net income of rural residents

Figure 2 shows the CCs for 2005. The CCs for the other years from 2003 to 2008 are all similar to the CCs for 2005 and are included in the Additional file 1. Figure 3 shows the CCs for 2010. The CCs for 2009 and 2011 are similar to the CCs for 2010 and are included in the Additional file 1. For every year, the $\mathrm{CC}$ of improved sanitation and the $\mathrm{CC}$ of net income of rural residents both lie below the line of absolute equity, but the $\mathrm{CC}$ of improved sanitation lies between the $\mathrm{CC}$ of net income of rural residents and the line of absolute equality. Based on this information, it can be interpreted that from 2003 to 2011, income and improved sanitation were more concentrated in regions with good economic statuses. However, the inequality in improved sanitation was less than the inequality in income for the years 2003 to 2011. From 2009 to 2011, during the 3-year health reform program, the CCs of central investment are all above the line of absolute equality. This shows that the distribution of central investment benefited the disadvantaged groups more than groups that were not disadvantaged.

\section{Cls of central investment, improved sanitation, and net} income of rural residents and $\mathrm{ACl}$ of improved sanitation Figure 4 presents the three CIs and the ACI. From 2003 to 2011, there is an obvious downtrend of the CI for net income of rural residents. The CI declines from 0.1844 in 2003 to 0.1599 in 2011, indicating that the inequality of rural residents' income decreased year by year. In the meantime, although it was lower than the CI for rural residents' net income, the CI for improved sanitation had been increasing from 2003 to 2008. However, it started to drop in 2009, and by 2011, the CI for improved sanitation had reached the same level as the CI for 2003.

The CIs of central investment for 2009, 2010, and 2011 are negative, indicating that investments had been more concentrated on poorer provinces and regions. The ACI of improved sanitation had a slight drop from 2003 to 2008, but declined sharply from 2009 to 2011. This means that the improved sanitation coverage rates for each province are increasing simultaneously, and thus the imparities among the provinces are narrowing. 


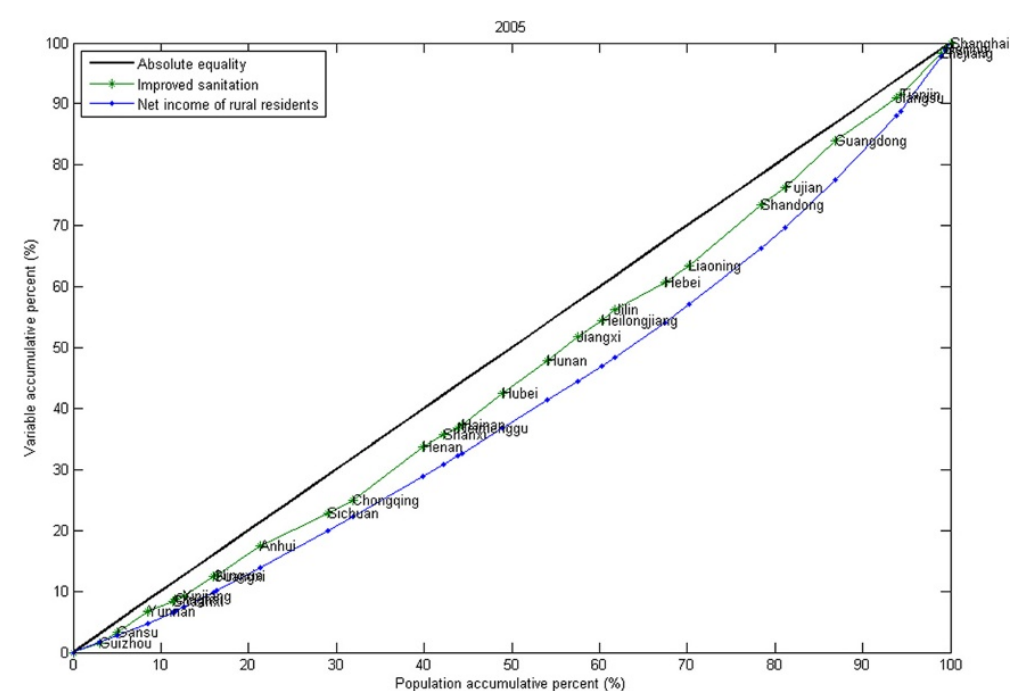

Figure 2 Concentration curves for 2005.

Change in improved sanitation coverage in east, west, and central China

Figure 5 indicates that improved sanitation coverage rates of east, west, and central China are increasing each year. However, from 2003 to 2008, there is a marked difference in improved sanitation coverage rate between west China and central China, as well as between west China and east China. In 2009, the difference began to narrow, and this is one main reason that the $\mathrm{CI}$ and ACI of improved sanitation had been decreasing since 2009 .

\section{Discussion}

Due to limited resources, determining how to make a fairer allocation of public resources often creates a dilemma for policymakers [30]. One of the reasons for this dilemma is the complexity involved in defining "equity" [31]. One element of defining equity is making a "value judgment" [32]. In recent years, many public service scholars have stated that the core ideology of equity or fairness indicates that input should vary as the needs of the population vary. In that case, the goal of equity is defined as equally attainable, which means public resources should be of the same attainability to people with the same needs for public services. When trying to achieve equity in public services or resource distribution, most industrialized countries would refer to the concept of "equally attainable". We therefore evaluated the equity in sanitation improvement of China by calculating the $\mathrm{CI}$ of improved sanitation, $\mathrm{CI}$ of central

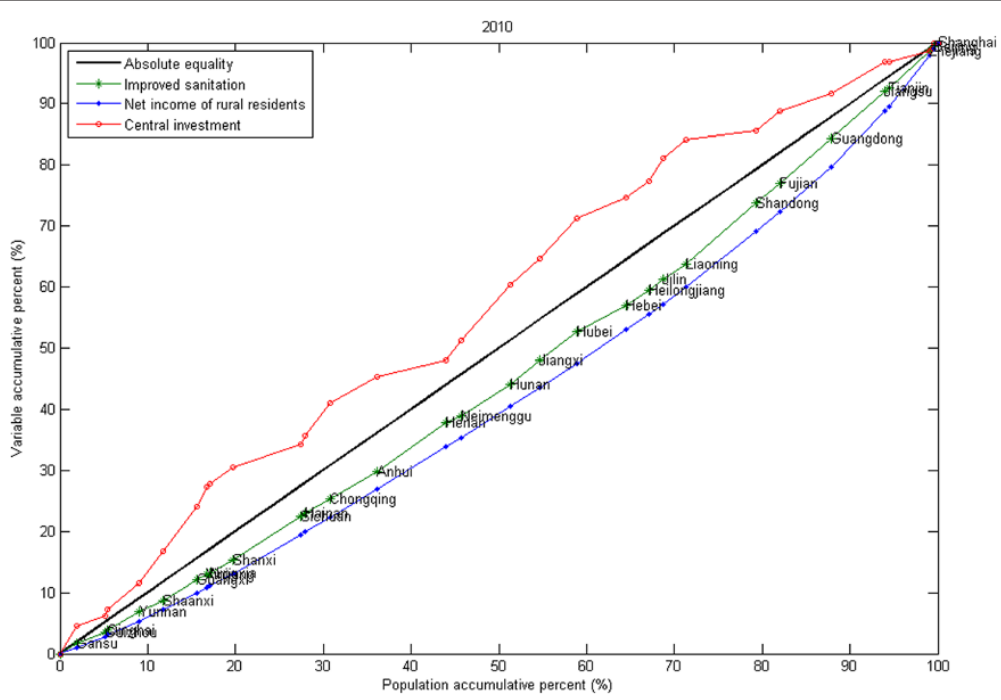

Figure 3 Concentration curves for 2010. 


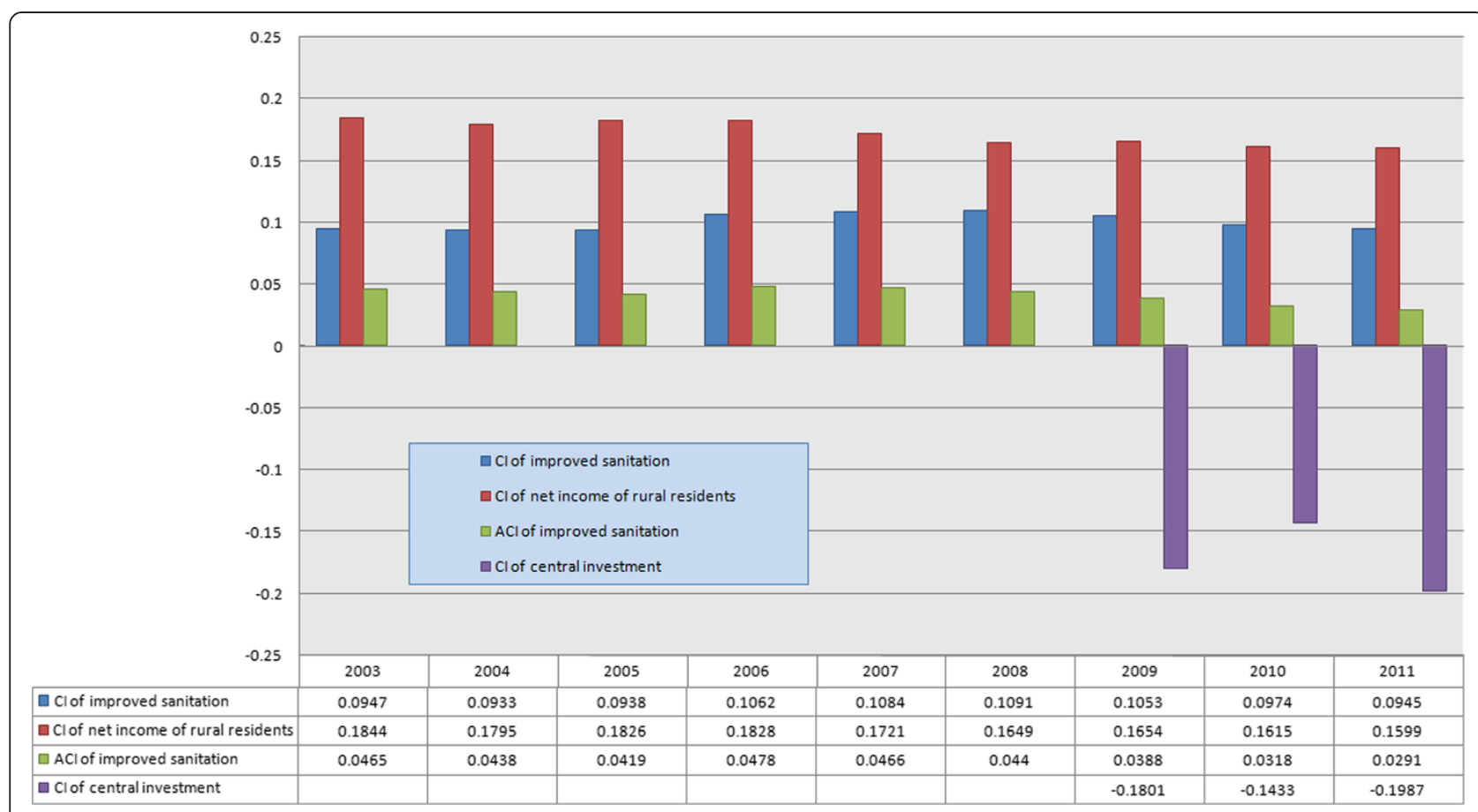

Figure $4 \mathrm{Cls}$ and $\mathrm{ACl}$ from 2003 to 2011.

investment, CI of rural residents' net income, and ACI of improved sanitation.

In terms of equity, judging from the CIs of improved sanitation, central investment, and rural residents' net income, the equality of rural residents' net income has been improving year by year. Meanwhile, equity in sanitation improvement deteriorated from 2003 to 2008. We believe the main cause of this deterioration is that the willingness of rural residents in east China to pay for improved sanitation is higher than that of rural residents central and west China [33]. Therefore, the disparity of the ratio of improved sanitation between the provinces in east China and the provinces in central and west China would increase without intervention. However, equity had become better starting in 2009, likely due to the central investment during the 3-year health reform program in sanitation improvement that benefits low-income populations more. The CIs of central investment from 2009 to 2011 are all negative, and the CCs are all above the line of absolute equality. On the other hand, west China, whose economy lags behind the economies of east and central China, had remarkably improved sanitation coverage as well. Some scholars indicated that the contributions of the main determinants of sanitation improvement (including economic status, minority status, education, and temperature) to the inequality of sanitation improvement

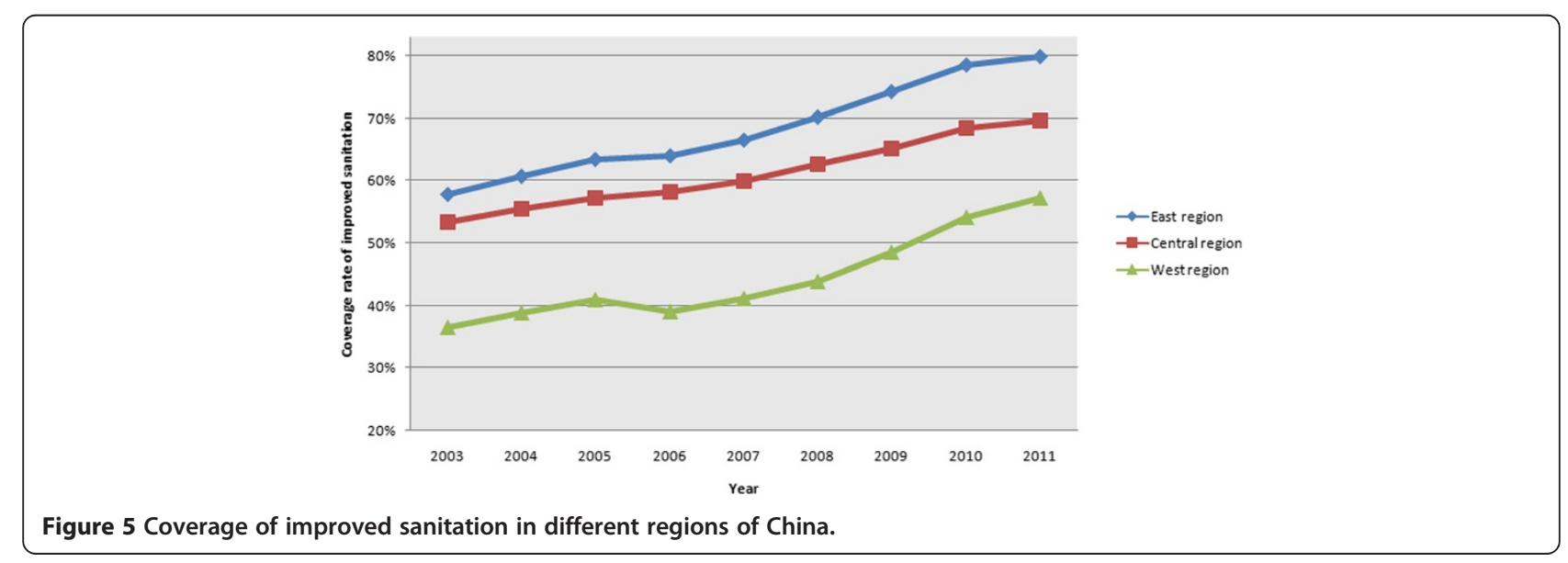


in China from 2003 to 2011 did not change substantially [34]. The 3-year health reform program therefore clearly played an important role in promoting equity in sanitation improvement. However, although the equity of sanitation improvement increased year by year as a result of the 3 -year health reform program, the situation may not be quite so optimistic from an overall perspective because equity in sanitation improvement in 2011 was the same as in 2003, although the equity of net income of rural residents had been increased.

Calculating ACIs, and not only relative CIs (as has been done in most previous studies), provides information on both the level and distribution of improved sanitation [18]. This is important because the aim of sanitation improvement policy, and all public health policy, is twofold: to improve the level and attain equity. The ACI thus provides a performance measure for the overarching aim of sanitation improvement policy.

Equity in sanitation improvement is difficult to measure, so we put forward a method to calculate the CI of improved sanitation that combines net income of rural residents with central investment in sanitation improvement to evaluate equity. It is also the first time a study has systematically evaluated sanitation improvement during these years in China. However, sanitation improvement is in fact influenced by many other factors, including climate and nationality $[23,34,35]$. How these factors influence the equity of sanitation improvement and any bottlenecks in further equity improvement must be included in further study. In addition, in this study, we only considered the variables that are easy to quantify, such as the ratio of improved sanitation and central investment. However, it is also important to consider variables such as knowledge, attitude and practice (KAP) which cannot be arrived at directly. We believe there is a marked effect of disparity in KAP on sanitation improvement in China and can strongly influence the ratio of improved sanitation. In addition, our study is based on provincial panel data for China, which means that the imparities we discussed are among provinces, not within each province. To determine provincial imparities, more detailed data are needed, such as data at the municipal level or county level.

The ultimate goal of evaluating equity in sanitation improvement is to eliminate inequity, which requires determining what caused the inequity so the bottleneck and any constraints on sanitation improvement can be removed individually. This is the common perspective of many researchers and related departments and an important research goal.

\section{Conclusion}

Using the approach of $\mathrm{CI}$ and $\mathrm{ACI}$, we found that the equality of rural residents' net income has been improving each year, whereas equity in sanitation improvement deteriorated from 2003 to 2008 . However, equity in sanitation improvement has increased since 2009 due to central investment in sanitation improvement during the 3-year health reform program, which benefits low-income areas more than higher-income areas. Based on this study, it is clear that the 3-year health reform program played an important role in promoting the level and equity of sanitation improvement in China.

\section{Additional file}

Additional file 1: Concentration curves for 2003 to 2012.

\section{Competing interests}

The authors declare that they have no competing interests.

\section{Authors' contributions}

$\mathrm{XL}$ conceived the idea for the paper and performed the main analyses. YM contributed to collecting data and provided guidance and overall quality control. WC contributed to correspondence to obtain data about the central investment in each province. All authors read and approved the final manuscript.

\section{Acknowledgements}

The authors acknowledge financial support from the UNICEF program "Inequity of Access to Sanitary Latrines in Rural China" and the National Development and Reform Commission. Zhenbo Yang of UNICEF provided great assistance with this study.

\section{Author details}

${ }^{1}$ School of Economics and Management, Beijing University of Posts and Telecommunications, Beijing 100876, China. ${ }^{2}$ China National Health Development Research Center, NHFPC, Beijing 100083, China.

Received: 10 July 2014 Accepted: 6 January 2015

Published online: 31 January 2015

\section{References}

1. Prüss-Üstün A, Bos R, Gore F, Bartram J: Safer water, better health: costs, benefits and sustainability of interventions to protect and promote health. Geneva: World Health Organization; 2008.

2. Boschi-Pinto C, Velebit L, Shibuya K. Estimating child mortality due to diarrhoea in developing countries. Bull World Health Organ. 2008;86(9):710-7.

3. Bartram J, Cairncross S. Hygiene, sanitation, and water: forgotten foundations of health. PLoS Med. 2010;7(11):e1000367.

4. Pardey PG, Alston JM, Piggott R. Agricultural R\&D in the developing world: Too little, too late? Washington, D.C: Intl Food Policy Res Inst; 2006.

5. Carlton EJ, Liang S, McDowell JZ, Li H, Luo W, Remais JV. Regional disparities in the burden of disease attributable to unsafe water and poor sanitation in China. Bull World Health Organ. 2012;90(8):578-87.

6. Zhang J, Mauzerall DL, Zhu T, Liang S, Ezzati M, Remais JV. Environmental health in China: progress towards clean air and safe water. Lancet. 2010;375(9720):1110-9.

7. Fang $P$, Dong S, Xiao J, Liu C, Feng X, Wang Y. Regional inequality in health and its determinants: evidence from China. Health Policy. 2010;94(1):14-25.

8. Zhang X, Xiong Y, Ye J, Deng Z, Zhang X. Analysis of government investment in primary healthcare institutions to promote equity during the three-year health reform program in China. BMC Heal Serv Res. 2013;13:114.

9. Implementation plan for the recent priorities of the health care system reform (2009-2011). Beijing: The State Council of China; 2009

10. Report on the implementation of central and local budgets for 2012. Beijing: Ministry of Finance; 2012

11. China Health Statistics Yearbook 2012. Peking Union Medical College Press. Beijing. 2012

12. Miao Y, Chen W, Gong Z, Lin Q. performance evaluation report of sanitation improvement in the rural areas. Beijing: China National Health Development Research Center CNHDR; 2013. 
13. Laiyun S. China Statistical Yearbook 2012. Beijing: China Statistics Press; 2012.

14. Periago MR. Health in the Americas. Washington, D.C: Pan American Health Organization; 2007

15. Cullis J, Koppen BC. Applying the Gini Coefficient to measure inequality of water use in the Olifants River water management area, South Africa. Colombo, Sri Lanka: International Water Management Institute; 2007.

16. Kirigia DG, Kirigia JM. Inequalities in selected health-related millennium development goals indicators in all WHO member states. Afr J Health Sci. 2008;14(3):171-86

17. Wang X-j, Zhang J-y, Shahid S, ElMahdi A, He R-m, Wang X-g, et al. Gini coefficient to assess equity in domestic water supply in the Yellow River. Mitig Adapt Strat Glob Chang. 2012;17(1):65-75

18. Ásgeirsdóttir TL, Ragnarsdóttir DÓ. Determinants of relative and absolute concentration indices: evidence from 26 European countries. Int J Equity Health. 2013;12:53.

19. Hernández-Quevedo C, Jones AM, López-Nicolás A, Rice N. Socioeconomic inequalities in health: a comparative longitudinal analysis using the European community household panel. Soc Sci Med. 2006;63(5):1246-61.

20. Gunasekara Fl, Carter K, McKenzie S. Income-related health inequalities in working age men and women in Australia and New Zealand. Aust N Z J Public Health. 2013;37(3):211-7.

21. Clarke $P$, Smith L, Jenkinson C. Health inequalities: comparing health inequalities among men aged 18-65 years in Australia and England using the SF-36. Aust N Z J Public Health. 2002;26(2):136-43.

22. Evans $B$, Colin $C$, Jones $H$, Robinson $A$. Sustainability and equity aspects of total sanitation programmes-A study of recent WaterAid-supported programmes in three countries: global synthesis report. London: WaterAid; 2009.

23. Whittington D, Lauria DT, Wright AM, Choe K, Hughes JA, Swarna V. Household demand for improved sanitation services in Kumasi, Ghana: a contingent valuation study. Water Resour Res. 1993;29(6):1539-60.

24. Chen J, Li Z, Gao X, Du H, Yu L, Ren H, et al. Toilet retrofit in rural areas of China:impact factors and effect analysis. Chin Rural Health Serv Adm. 2013:002:181-3.

25. Hossain SI. Making an equitable and efficient education: the Chinese experience. China: Social Sector Expenditure Review, World Bank; 1996

26. Kakwani N, Wagstaff A, Van Doorslaer E. Socioeconomic inequalities in health: measurement, computation, and statistical inference. J Econ. 1997;77(1):87-103.

27. Wagstaff A, Van Doorslaer E. Income inequality and health: what does the literature tell us? Annu Rev Public Health. 2000;21(1):543-67.

28. Wagstaff A, Van Doorslaer E, Watanabe N. On decomposing the causes of health sector inequalities with an application to malnutrition inequalities in Vietnam. J Econ. 2003;112(1):207-23.

29. O'Donnell OA, Wagstaff A. Analyzing health equity using household survey data: a guide to techniques and their implementation. Washington, D.C World Bank Publications; 2008.

30. Braveman P, Starfield B, Geiger HJ. World health report 2000: how it removes equity from the agenda for public health monitoring and policy. Br Med J. 2001;323(7314):678

31. Starfield B. Pathways of influence on equity in health. Soc Sci Med. 2007;64 (7):1355-62.

32. Mooney G, Jan S, Wiseman V. Staking a claim for claims: a case study of resource allocation in Australian Aboriginal health care. Soc Sci Med. 2002;54(11):1657-67.

33. Yanqing $M$, Zhenbo $Y$, Heyu Z. Study on rural residents' willingness to pay to sanitation and influencing factors in China: the improvement of rural sanitary toilets as example. Manage World. 2012:9889-99.

34. Xiaolong L, Yazhou G, Yanqing M, Wenjing C. Understanding determinants of inequality in sanitation improvement in Rural China. Iran J Public Health. 2014:43(8):1148-9.

35. Kar K, Pasteur K. Subsidy or self-respect? Community led total sanitation. An update on recent developments. Brighton: Institute of Development Studies; 2005.

\section{Submit your next manuscript to BioMed Central and take full advantage of:}

- Convenient online submission

- Thorough peer review

- No space constraints or color figure charges

- Immediate publication on acceptance

- Inclusion in PubMed, CAS, Scopus and Google Scholar

- Research which is freely available for redistribution 